\title{
Investigation of Corrosion and Cathodic Protection in Reinforced Concrete
}

\section{Properties of Steel Surface Layers}

\author{
D. A. Koleva, ${ }^{\text {a,*,z }}$ J. H. W. de Wit, ${ }^{\text {b,* }}{ }^{\text {K. van Breugel, }}{ }^{\text {a }}$ Z. F. Lodhi, ${ }^{c}$ and G. Ye ${ }^{\text {a }}$ \\ ${ }^{a}$ Faculty of Civil Engineering and Geosciences, Section Material Science, and ${ }^{b}$ Faculty of Mechanical, \\ Maritime, and Materials Engineering, Deft University of Technology, 2628 CD Delft, \\ The Netherlands \\ ${ }^{c}$ Netherlands Institute for Metal Research, 2628 CD Delft, The Netherlands
}

The present study explores the formation of corrosion products on the steel surface (using as-received low carbon construction steel) in reinforced concrete in conditions of corrosion and subsequent transformation of these layers in conditions of cathodic protection $(\mathrm{CP})$. Of particular interest was to investigate whether the introduced pulse $\mathrm{CP}$ (a cost-effective alternative to $\mathrm{CP}$ ) will lead to similar or even more favorable conversion of the product layers on the steel surface, compared to conventional techniques. Qualification and quantification of the studied layers was performed using X-ray diffraction, X-ray photoelectron spectroscopy, and energy dispersive analysis, visualization of morphology and products distribution was achieved using environmental scanning electron microscopy. The steel surface was found to be covered by a layered, nonhomogeneous formation of products, differing in crystallinity and composition, comprising an inner layer, similar to $\mathrm{Fe}_{3} \mathrm{O}_{4}$, and an outer layer, composed of iron (oxy)hydroxides and iron (oxy)hydroxy-chlorides [i.e., a combination of $\alpha-, \beta, \gamma-\mathrm{FeOOH}, \mathrm{Fe}(\mathrm{O}, \mathrm{OH}, \mathrm{Cl})$, and $\mathrm{Fe}_{2} \mathrm{O}_{3}$ ]. The product layer in corroding specimens is a combination of low valent oxides and iron-oxy(hydroxy)chlorides, exhibiting a relatively rough morphology. The product layers in the protected specimens were far more compact. Cathodic protection reduces salinity around the steel bars, hence the inner product layer $\left(\right.$ mostly $\mathrm{Fe}_{3} \mathrm{O}_{4}$ ) remains more uniform, whereas the outer layer exhibits reduced crystallinity. The favorable transformation phenomena were found to be more apparent under pulse CP conditions, attributed to the obviously beneficial effects of pulse CP in terms of enhanced chloride withdrawal from the steel surface and minor influence (less side effects) on the bulk concrete microstructure.

(C) 2007 The Electrochemical Society. [DOI: 10.1149/1.2715313] All rights reserved.

Manuscript submitted July 10, 2006; revised manuscript received January 18, 2007. Available electronically March $23,2007$.

The most common and important causes for reinforcement corrosion are either localized depassivation of the steel surface due to chloride ingress or more uniform corrosion due to acidification of the pore solution as result of carbonation of the cement paste. Cathodic protection $(\mathrm{CP})$ has been found to be one of the most useful techniques for inhibiting chloride-induced corrosion in reinforced concrete. ${ }^{1}$ The fundamental mechanisms underlying the efficiency of $\mathrm{CP}$ techniques are strongly correlated to the morphology and transformations of product layers on the steel surface. The steel reinforcement used in the present study was as-received construction steel FeB500HKN (rebars, $d=12 \mathrm{~mm}, C<0.22 \mathrm{wt} \%$. Electrochemical impedance spectroscopy (EIS), polarizations resistance (PR) method, and potentio-dynamic polarization (PDP) were used for a comparative analysis of electrochemical parameters and corrosion behavior of the embedded steel in the reinforced concrete specimens presented here, in the relevant conditions of corrosion and $\mathrm{CP}$, and the outcomes were reported previously. ${ }^{2}$ This paper pursues exploration of the formation, distribution, and morphological alterations of corrosion products in the reinforced concrete specimens in conditions of corrosion and CP. Moreover, this study aims to reveal the advantages of an improved alternative of the conventional $\mathrm{CP}$, denoted in the paper as pulse $\mathrm{CP}$, in terms of favorable structure of the product layers formed under pulse CP conditions, compared to those observed under the conventional techniques of protection.

In a simplified way, corrosion of steel in reinforced concrete can be represented by two electrochemical reactions: dissolution of iron at anodic sites (Eq. 1) and the corresponding oxygen reduction at local cathodes, using the electrons generated by the metal dissolution (Eq. 2)

$$
\begin{gathered}
2 \mathrm{Fe} \rightarrow 2 \mathrm{Fe}^{2+}+4 \mathrm{e}^{-} \\
\mathrm{O}_{2}+2 \mathrm{H}_{2} \mathrm{O}+4 \mathrm{e}^{-} \rightarrow 4 \mathrm{OH}^{-}
\end{gathered}
$$

The products of the above reactions normally interact and in a final stage transform into a stable protective film on the steel sur-

\footnotetext{
*lectrochemical Society Active Member.

z E-mail: D.A.Koleva@TUDelft.nl
}

face. In the simplest case, a two layer structure of the film can be assumed, where the inner layer, ascribed $\mathrm{Fe}_{3} \mathrm{O}_{4}$, acts as a barrier layer, strongly adhering to the steel surface and limiting further film growth. ${ }^{3}$ Passivity though, is assigned to the outer, gelatinous type layer, composed of outer hydrous $\mathrm{Fe}_{2} \mathrm{O}_{3}$. The protective layer is additionally supported by the presence of a Ca-rich outer layer, which adheres to the steel as well. According to some researchers, the calcium rich layer provides only limited protection, the inner (two layer) film of iron oxide/hydroxides is the one passivating the steel. ${ }^{4}$ Other investigations ${ }^{3,5}$ attribute increased protective ability of the passive layers to incorporated $\mathrm{Ca}(\mathrm{OH})_{2}$ in the outer atom layers of the inner passivating film. The mechanism is denoted to adsorption of $\mathrm{Ca}^{2+}$ ions in the inner film of iron oxide/hydroxides.

The protective abilities of the passive films (the outer layer as well) are strongly dependent on the electrode potential, the $\mathrm{pH}$ of the adjacent solution, and the presence of aggressive ions (as chloride in this study). In general, $\mathrm{pH}$ in concrete is about 12.5-13.5 and oxygen availability is comparatively restricted in the case of sound concrete layer on the steel surface, hence passivity could be stable with time. However, in the presence of aggressive substances, moisture, and microcracks, which favor oxygen and aggressive substances penetration to the vicinity of the steel surface, breakdown of passivity occurs and corrosion is initiated. The passive layer breakdown mechanisms were extensively studied by numerous authors ${ }^{6-9}$ and a number of models are already proposed and described; for example, the adsorption-displacement, the chemico-mechanical, and the migration-penetration mechanism.

Whatever the mechanism of protective film breakdown, the final stage is exposure of small areas of the metal surface to the electrolyte (in this case to the pore solution). Once corrosion is initiated, film transformations or formation of new product layers occur. There are several possibilities for the formation sequence of these layers, depending on the environmental conditions. In conditions of $\mathrm{CP}$, transformations of the product layers, formed prior to protection, occur as well, mainly in terms of lowering the products crystallinity and leading to the formation of a more compact layer on the steel surface. The favorable conversions are more pronounced under pulse $\mathrm{CP}$ conditions compared to conventional $\mathrm{CP}$ and are attributed 
to the beneficial effects of pulses in reducing pore water salinity and favorable physico-chemical and microstructural alterations in the bulk cement paste.

\section{Review of Some Fundamental Mechanisms}

The corrosion process in reinforced concrete.- As mentioned, corrosion of steel in reinforced concrete could possibly occur in certain conditions, leading to passivity breakdown. The passivity breakdown is not subject to the present contribution, some fundamental mechanisms only are further presented, aiming at better understanding of the involved conversions, relevant to the conditions of the present study.

In a simplified way, the dissolution of iron according Eq. 1 can further proceed in development of an oxide film. This film is either a combination or a predominant occurrence of ferrous $\left(\mathrm{Fe}^{2+}\right)$ or ferric $\left(\mathrm{Fe}^{3+}\right)$ in nature compounds. Both are chemically stable in concrete in the absence of carbonation or chlorides. With aging and depending on oxygen availability, the ferrous oxides convert to more stable ferric oxides.

The development of the oxide film following Eq. 1 proceeds as

$$
\begin{gathered}
\mathrm{Fe}^{2+}+2 \mathrm{OH}^{-} \rightarrow \mathrm{Fe}(\mathrm{OH})_{2} \\
\mathrm{Fe}(\mathrm{OH})_{2}+\frac{1}{4} \mathrm{O}_{2^{-}} \rightarrow \gamma-\mathrm{FeOOH}+\frac{1}{2} \mathrm{H}_{2} \mathrm{O}
\end{gathered}
$$

Basically, when chlorides are present in the cement layers, adjacent to the steel surface (or in case of carbonation), soluble complexes are formed from ferrous oxides, as for example according, ${ }^{10}$

$$
\begin{aligned}
4 \mathrm{Fe}(\mathrm{OH})_{2}+\mathrm{Cl}^{-} \rightarrow & {\left[\mathrm{Fe}_{3}^{2+} \mathrm{Fe}^{3+}(\mathrm{OH})_{8} \mathrm{Cl}\right]+\mathrm{e}^{-} } \\
6 \mathrm{Fe}(\mathrm{OH})_{2}+\mathrm{CO}_{3}^{2-}+2 \mathrm{H}_{2} \mathrm{O} \rightarrow & {\left[\mathrm{Fe}_{4}^{2+} \mathrm{Fe}_{2}^{3+}(\mathrm{OH})_{12}\right]\left[\mathrm{CO}_{3} \cdot 2 \mathrm{H}_{2} \mathrm{O}\right] } \\
+ & 2 \mathrm{e}^{-}
\end{aligned}
$$

which could further dissolve in the steel surrounding, i.e., intermediate compounds are formed, they are not protective and do not accommodate in an adherent product layer.

The intermediate phases, having hexagonal and cubic layers of close-packed oxygen (as green rusts I and II (Eq. 5 and 6), $\mathrm{Fe}(\mathrm{OH})_{2}$ ) exist before the appearance of end products, having purely cubic close-packed structures $\left(\right.$ as $\mathrm{Fe}_{3} \mathrm{O}_{4}$ (being $\mathrm{FeO}+\mathrm{Fe}_{2} \mathrm{O}_{3}$ ), $\gamma$ - $\mathrm{FeOOH}$, or $\left.\gamma-\mathrm{Fe}_{2} \mathrm{O}_{3}\right) .{ }^{11}$ Furthermore, in the presence of $\mathrm{Cl}^{-}$, stability of cubic close packed (CCP) arrangement is more favored than hexagonal close packing (HCP) of oxygen. ${ }^{12}$ Hence, in case the oxide film is mostly ferric oxide in nature, it will be more resistant to chlorides, compared to an oxide film of ferrous oxides, as also reported in Ref. 13.

According to one of the existing models for chloride-induced passivity breakdown, initial adsorption of chloride anions on the oxide film might take place, ${ }^{9}$ which finally leads to its chemical dissolution. This mechanism is known to be very local in character ${ }^{6}$ and takes place mostly on structural defects or inhomogeneities on the surface. ${ }^{7}$ As already described above, this film is layered in character and can undergo a variety of transformations, depending on the adjacent medium. ${ }^{5,8,14,15}$ One of the possible interactions is that chloride anions adsorption enables new charge exchange pathways, which allow the steel surface to corrode. ${ }^{6}$ The occurrence of these new charge exchange pathways, could be one of the most likely mechanisms of chloride induced corrosion in reinforced concrete.

In reinforced concrete subjected to chloride environments, the chlorides are found to be either free or bound. Bound chlorides can participate in the corrosion process if a $\mathrm{pH}$ drop occurs, as in the case of carbonation for example. Carbonation is the process by which atmospheric $\mathrm{CO}_{2}$ slowly (depending on the concrete microstructure) propagates in depth the bulk concrete.

According to a simplified model, ${ }^{16}$ the carbonation process proceeds as follows:

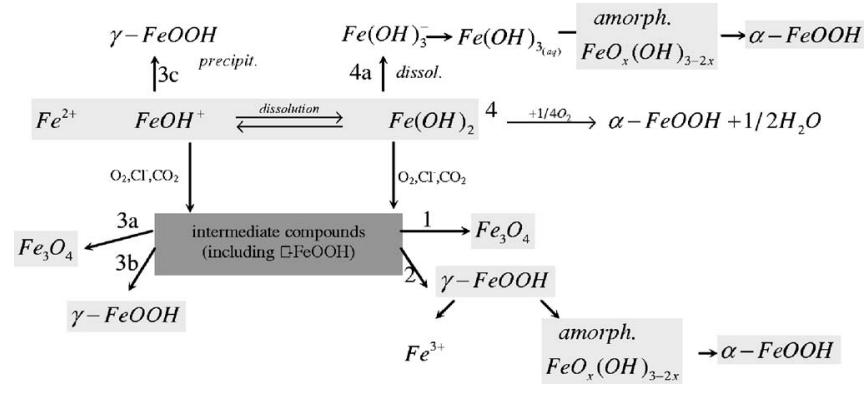

Figure 1. Possible interactions and product formation in the $\mathrm{Fe}-\mathrm{H}_{2} \mathrm{O}$ system.

1. $\mathrm{CO}_{2}$ penetration through the concrete cover

2. $\mathrm{CO}_{2}$ dissolution in the pore solution and reaction with $\mathrm{Ca}(\mathrm{OH})_{2}$

$$
\mathrm{Ca}(\mathrm{OH})_{2}+\mathrm{CO}_{2} \rightarrow \mathrm{CaCO}_{3}+\mathrm{H}_{2} \mathrm{O}
$$

3. Reaction with silicates and aluminates according to

$$
\begin{array}{r}
2 \mathrm{SiO}_{2} \cdot 3 \mathrm{CaO} \cdot 3 \mathrm{H}_{2} \mathrm{O}+3 \mathrm{CO}_{2} \rightarrow 2 \mathrm{SiO}_{2}+3 \mathrm{CaCO}_{3}+3 \mathrm{H}_{2} \mathrm{O} \\
4 \mathrm{CaO} \cdot \mathrm{Al}_{2} \mathrm{O}_{3} \cdot 13 \mathrm{H}_{2} \mathrm{O}+4 \mathrm{CO}_{2} \rightarrow 2 \mathrm{Al}(\mathrm{OH})_{3}+4 \mathrm{CaCO}_{3}+10 \mathrm{H}_{2} \mathrm{O}
\end{array}
$$

Furthermore, in the presence of water and excess of $\mathrm{CO}_{2}$, bicarbonate formation is possible, which lowers the $\mathrm{pH}$ in concrete

$$
\mathrm{CaCO}_{3}+\mathrm{H}_{2} \mathrm{O}+2 \mathrm{CO}_{2} \rightarrow \mathrm{Ca}\left(\mathrm{HCO}_{3}\right)_{2}
$$

The above reactions lead to $\mathrm{pH}$ drop in the cement pore solution (as reported around $\mathrm{pH} 8^{13}$ ) which consequently leads to dissolution of calcium-chloro-aluminates (the bound chlorides) and along with local acidification, increases the free chloride concentration and to localized corrosion, i.e., breakdown of passivity in local areas. The metal dissolution in these areas creates locally increased concentration of metallic ions in addition to aggressive ions, migrating from the bulk solution to the steel surface.

Formation of product layers. - Several mechanisms are presented for the $\mathrm{Fe}-\mathrm{H}_{2} \mathrm{O}$ system in what follows, not taking into consideration the cement chemistry for simplicity. The reaction products in the $\mathrm{Fe}-\mathrm{H}_{2} \mathrm{O}$ system are normally determined not only by thermodynamic relationships, ${ }^{11}$ but by the oxidation rate of $\mathrm{Fe}^{2+}$ and the structure and composition of initial and intermediate iron species, as reported in Ref. 17. As introduced above, with chloride induced corrosion, intermediate compounds are inevitably formed in the vicinity of the steel reinforcement, which further decompose or influence the formation of the "final" product layers, as further oxidation or reduction is governed by their existence. According to Ref. 17, the intermediate compounds are formed either by precipitation from the so called "green complexes," the latter produced by coexisting anions as chloride ions during oxidation of $\mathrm{FeOH}^{+}$, or by solid state transformation of $\mathrm{Fe}(\mathrm{OH})_{2}$ with oxidation. The mechanisms for products formation are complicated and depend on a variety of environmental factors and oxidation stages.

A simplified scheme, based on the transformations suggested by Ref. 17 is presented in Fig. 1. The formation of $\mathrm{Fe}_{3} \mathrm{O}_{4}$ from $\mathrm{Fe}(\mathrm{OH})_{2}$ can be classified into two routes (1 and 3a, Fig. 1). Route 1, slow oxidation, ending up with mainly $\mathrm{Fe}_{3} \mathrm{O}_{4}$ as final product, is more likely for reinforced concrete systems, where oxygen availability is reduced and especially for such systems under cathodic protection, where the negative (cathodic) potential and the consumption of oxygen due to the $\mathrm{CP}$ are promoting mainly $\mathrm{Fe}_{3} \mathrm{O}_{4}$.

The intermediate compounds can be converted to $\gamma$ - $\mathrm{FeOOH}$ as well, consequently to amorphous oxy-hydroxide layer or $\alpha-\mathrm{FeOOH}$ (path 2). This transformation is more likely for the corroding speci- 
mens in the present study, as the hydroxides and amorphous products would be dominant for the potential range (mostly more anodic than $-650 \mathrm{mV} \mathrm{SCE}$ ), the locally low $\mathrm{pH}$ and higher oxygen supply to the steel surface (through the formed cracks due to volume expansion of corrosion products) for these specimens.

As reported in Ref. 17, a direct spontaneous transition from $\mathrm{Fe}(\mathrm{OH})_{2}$ to $\mathrm{Fe}_{3} \mathrm{O}_{4}$ or $\gamma$ - $\mathrm{FeOOH}$, although thermodynamically possible, ${ }^{11}$ seems difficult in terms of transition from hexagonal closed-packed structure of oxygen $\left[\mathrm{Fe}(\mathrm{OH})_{2}\right]$ directly to cubic closed-packed structure $\left(\mathrm{Fe}_{3} \mathrm{O}_{4}\right.$ and $\left.\gamma-\mathrm{FeOOH}\right)$. Hence, the transformation occurs via intermediate compounds [complex compounds, similar to green rusts, denoted as $\left.\mathrm{Fe}_{x} \mathrm{O}_{y} \cdot \mathrm{GR}\left(\mathrm{CO}_{3}^{2-}\right)\right]$, having both structures. Such intermediate compounds are identified in the corroding specimens in this study, exhibiting granularly porous or layered deposits. These deposits are most probably $\mathrm{Fe}_{3} \mathrm{O}_{4} \cdot \mathrm{GR}\left(\mathrm{CO}_{3}^{2-}\right)$, (which forms in the conversion process of $\mathrm{Fe}(\mathrm{OH})_{2}$ to $\mathrm{Fe}_{3} \mathrm{O}_{4}$ or $\gamma$-FeOOH), being composed of $\mathrm{Fe}(\mathrm{OH})_{2}: \mathrm{Fe}(\mathrm{OH})_{3}$ with intercalated $\mathrm{CO}_{3}^{2-}$, also reported by Ref. 18 .

In conditions of relatively poor oxygen supply (as in reinforced concrete), the oxidation of the intermediate compounds proceeds slowly, hence $\mathrm{Fe}_{3} \mathrm{O}_{4}$ can be directly formed, which explains the expected (and identified) higher amounts of magnetite in the protected specimens in this study (protection was applied at 120 days of age, when corrosion was in an advanced stage already). In case of more rapid oxidation (as in the corroding specimens), the structural rearrangement is not following the formation of $\mathrm{Fe}_{3} \mathrm{O}_{4}$, but formation of $\gamma-\mathrm{FeOOH}$ via amorphous oxyhydroxides (path 2).

Similar mechanisms for neutral and alkaline solutions, account for the formation of $\mathrm{Fe}_{3} \mathrm{O}_{4}$ and $\gamma-\mathrm{FeOOH}$ from $\mathrm{FeOH}^{+}$(paths $3 \mathrm{a}$ to $3 \mathrm{c}$ ), with predominant formation of $\mathrm{Fe}_{3} \mathrm{O}_{4}$ for the protected specimens (thermodynamically and $\mathrm{CP}$ favored) and $\gamma-\mathrm{FeOOH}$ formation in the corroding specimens.

It is also possible for the final $\gamma-\mathrm{FeOOH}$ to precipitate directly by oxidation of ferrous solutions, i.e., in conditions of enriched of $\mathrm{Fe}^{2+}$ pore solution in the vicinity of the steel reinforcement in corroding conditions, accompanied by acidification due to passivity breakdown on the anodic sites (path 3c).

$\alpha-\mathrm{FeOOH}$ and amorphous ferric oxyhydroxides can be found as precipitates from $\mathrm{Fe}^{2+}$ [direct transformation from $\mathrm{Fe}(\mathrm{OH})_{2}$ ] in strongly basic solutions, as in the systems under study (path 4 and $4 a)$. Indeed, in all types of specimens, $\alpha-\mathrm{FeOOH}$ is present in much lower amounts and crystallinity, though for the protected specimens, compared to corroding specimens. In addition, possible formation of $\alpha-\mathrm{FeOOH}$ is favored by the high solubility of the ferrous hydroxocomplex $\mathrm{Fe}(\mathrm{OH})^{-3}\left(\mathrm{HFeO}^{2-}\right)$, the latter being dominant in the $\mathrm{pH}$ region 12-14 along with electrode potential range more cathodic than $-1 \mathrm{~V}$ vs a saturated calomel electrode (SCE) (as recorded in $\mathrm{CP}$ applications). The $\mathrm{Fe}(\mathrm{OH})_{3(\mathrm{aq})}$, participating in the former transformation (path 4a) is electro neutral and after polymerization to colloidal $\left[\mathrm{Fe}(\mathrm{OH})_{3}\right]_{\mathrm{n}}$ and in the presence of $\mathrm{OH}^{-}$in the pore solution, $\left(\mathrm{OH}^{-}\right.$always available at the steel surface in the protected specimens due to the cathodic reaction), it precipitates to amorphous ferric oxyhydroxide $\left[\mathrm{FeO}_{x}(\mathrm{OH})_{3-2 x}\right]$, which converts to $\alpha-\mathrm{FeOOH} .{ }^{19,20}$

In the presence of chlorides, as in this study, $\beta-\mathrm{FeOOH}$ (akaganeite) can be formed as well by hydrolysis of ferric solutions containing $\mathrm{Cl}^{-}$. Akaganeite is normally present in less adherent rust layers $^{21}$ on steel surface exposed to chloride environment. For the present conditions, a most likely mechanism is the formation of $\beta-\mathrm{FeOOH}$ by dry oxidation of $\beta-\mathrm{Fe}_{2}(\mathrm{OH})_{3} \mathrm{Cl}$ as suggested by Ref. 22 and $23 . \beta-\mathrm{FeOOH}$ and iron oxy(hydroxy)compounds were found in the corroding specimens and only at earlier stages in the protected specimens.

\section{Materials and Methods}

The materials used in the present study were reinforced concrete cylinders, cast from OPC CEM I 32.5 (casting according EN 196-1),

\begin{tabular}{|c|c|c|c|c|}
\hline \multicolumn{2}{|c|}{$\begin{array}{l}\text { Chemical composition } \\
\text { OPC CEM I } 32.5 \text { R }\end{array}$} & \multicolumn{2}{|c|}{$\begin{array}{c}\text { Constituents of } \\
\text { OPC CEM I } 32.5 \text { R }\end{array}$} & \multirow[b]{2}{*}{ Mixing proportions } \\
\hline Oxide & $\begin{array}{l}\text { Weight } \\
(\%)\end{array}$ & Phase $^{\mathrm{a}}$ & $\begin{array}{l}\text { Weight } \\
(\%)\end{array}$ & \\
\hline $\mathrm{CaO}$ & 6.90 & $\mathrm{C}_{3} \mathrm{~S}$ & 63 & Water/cement ratio: 0.6 \\
\hline $\mathrm{SiO}_{2}$ & 21.00 & $\mathrm{C}_{2} \mathrm{~S}$ & 13 & $\begin{array}{l}\text { Cement/sand/gravel } \\
\text { ratio: } 1: 2: 4\end{array}$ \\
\hline $\mathrm{Al}_{2} \mathrm{O}_{3}$ & 5.03 & $\mathrm{C}_{3} \mathrm{~A}$ & 8 & $\begin{array}{l}\text { Sand range: } 125 \mu \mathrm{m} \\
\text { to } 2 \mathrm{~mm}\end{array}$ \\
\hline $\mathrm{SO}_{3}$ & 3.00 & $\mathrm{C}_{4} \mathrm{AF}$ & 9 & $\begin{array}{l}\text { Gravel range: } 2 \mathrm{~mm} \\
\text { to } 12 \mathrm{~mm}\end{array}$ \\
\hline $\mathrm{Fe}_{2} \mathrm{O}_{3}$ & 2.83 & & & $\begin{array}{l}\text { Mixing and casting } \\
\text { EN 196-1 }\end{array}$ \\
\hline $\mathrm{MgO}$ & 2.00 & & & $\begin{array}{l}\text { Cement content: } \\
300 \mathrm{~kg} / \mathrm{m}^{3}\end{array}$ \\
\hline $\mathrm{Na}_{2} \mathrm{O}$ & 0.24 & & & \\
\hline $\mathrm{K}_{2} \mathrm{O}$ & 0.65 & & & \\
\hline $\mathrm{TiO}_{2}$ & 0.30 & & & \\
\hline $\mathrm{P}_{2} \mathrm{O}_{5}$ & 0.16 & & & \\
\hline $\mathrm{Mn}_{2} \mathrm{O}_{3}$ & 0.06 & & & \\
\hline
\end{tabular}

water to cement ratio 0.6 , cement to sand to gravel ratio 1:2:4 (Table I). The reinforced concrete cylinders had dimensions: $H=25 \mathrm{~cm}$, $D=12 \mathrm{~cm}$, containing embedded construction steel (FeB500HKN rebars, $d=12 \mathrm{~mm}$ ), used as received (no preliminary treatment) for all technical conditions. The experimental setup, as used in Ref. 2, is presented on Fig. 2. Cross sections of the steel/cement paste interface in a conditioned (protected in this case) and as received (not conditioned) steel bars are presented on Fig. 3, revealing the product layer, formed on the steel surface with time of the experiment in the former case and lack of product layer on the surface of the as received (and never cast in concrete) specimen in the latter case. For clarity, we would like to add that reinforcing steel, used in some large construction markets, has in the as-produced condition a relatively thick (many micrometers) high-temperature mill scale. The surface evolution of such material in service and under electrochemical protection regimes may differ significantly from that documented here for an initially scale-free reinforcing steel.

More detailed information for the morphology and composition of product layers in the investigated conditions are reported in Part I of this work ${ }^{2}$ in relation to electrochemical parameters. The steel bars in all investigated specimens were initially equal in surface preparation (as received, depicted on Fig. 3b). As reported in Ref. 24, as-received steel bars behave similarly to prerusted bars and exhibit even higher corrosion current densities, compared to sandblasted bars in equal conditions similar to the present study $(\mathrm{pH}$ $\sim 12.6$ and sufficiently high chloride concentration). Thus, presuming equal appearance of the steel surface before conditioning, the comparison of product layers after maintaining the steel reinforcement in the relevant technical conditions is considered accurate (as the comparison reflects the changes with conditioning time of initially same specimens).

Aiming at initiation of corrosion, the specimens were maintained in a salt spray chamber ( $\mathrm{SSC}$, using $5 \% \mathrm{NaCl}, 25$ to $35^{\circ} \mathrm{C}$ ) for 460 days after curing in fog room conditions $\left(98 \% \mathrm{RH}\right.$ and $\left.20^{\circ} \mathrm{C}\right)$ for 28 days.

Four main groups of specimens were investigated: a freely corroding group, a noncorroding group, a group with applied conventional $\mathrm{CP}$, and a group with applied pulse CP.

Cathodic protection was employed in the two regimes (conventional and pulse), using dc current in the range of 5 to $20 \mathrm{~mA} / \mathrm{m}^{2}$ 

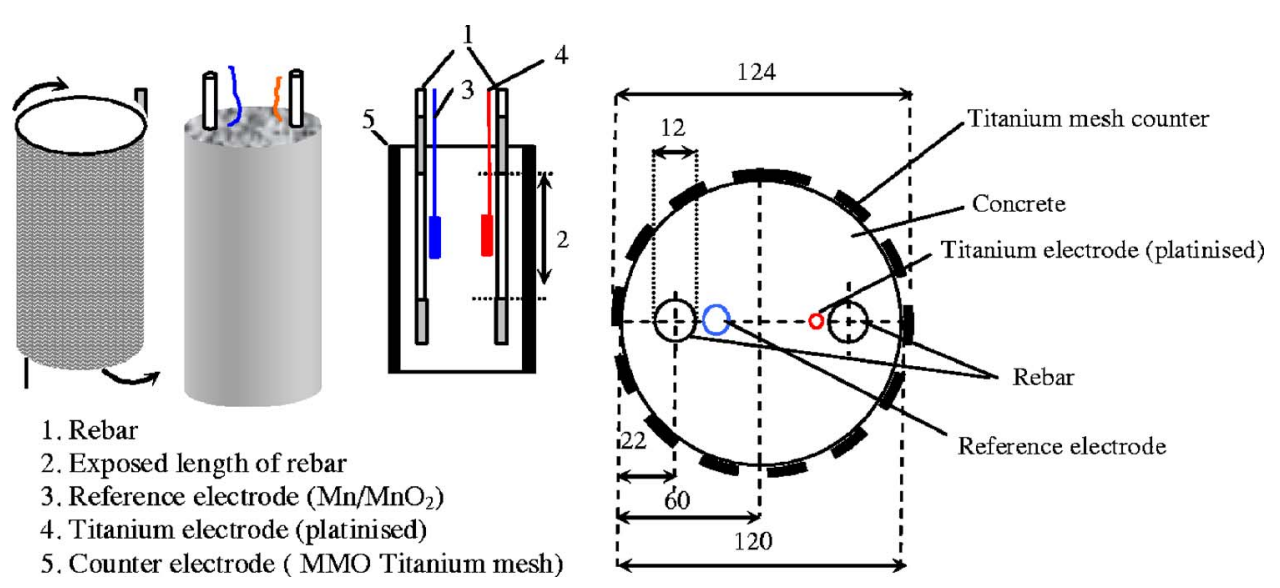

Figure 2. (Color online) Experimental setup.

steel surface; duty cycle for the pulse regime was $12.5 \%-50 \%$ at $1 \mathrm{kHz}$ frequency; mixed metal oxide (MMO) Ti mesh served as anode. The protection was applied after corrosion was initiated; the presented results are for specimens, on which $\mathrm{CP}$ (current density $20 \mathrm{~mA} / \mathrm{m}^{2}$ steel surface and $25 \%$ duty cycle at $1 \mathrm{kHz}$ frequency for the pulse regime) was applied at 120 days of age, i.e., in the time of applying protection, corrosion was already in an advanced stage. The collected data in this study are for 270 days of age, when conditioning of the specimens was interrupted for investigation.

The product layers on the corroding and the protected steel surfaces were observed using X-ray diffraction (XRD), X-ray photoelectron spectroscopy (XPS), energy dispersive X-ray (EDAX) analysis, and scanning electron microscopy (SEM).

For the XRD measurements, an X-ray powder diffractometer DRON-3 (Bragg-Brentano arrangement, $\mathrm{Cu} \mathrm{K} \alpha$ radiation, and scintillation counter) was used.

The XPS measurements were carried out using ESCALAB MkII (VG Scientific) electron spectrometer at a base pressure in the analysis chamber of $5 \times 10^{-10} \mathrm{mbar}$ (during the measurement $1 \times 10^{-8}$ mbar). The photoelectrons were excited using $\mathrm{Al} \mathrm{K} \alpha$ $\mathrm{X}$-ray source (excitation energy $h v=1486.6 \mathrm{eV}$ ). The pass energy of the analyzer was $20 \mathrm{eV}$ (for $\mathrm{Fe} 2 \mathrm{p}-50 \mathrm{eV}$ ). The instrumental resolution measured as the full width at a half-maximum (fwhm) of the $\mathrm{Ag} 3 \mathrm{~d} 5 / 2$, photoelectron peak is $1 \mathrm{eV}$. The energy scale was corrected to the $\mathrm{C} 1 \mathrm{~s}$ peak maxima at $285 \mathrm{eV}$.

SEM and EDAX investigations were performed with an environmental SEM, ESEM Philips XL 30, equipped with secondary, backscattered and large field detectors, operating at accelerating voltage of $20-25 \mathrm{kV}$ for imaging and $10-20 \mathrm{kV}$ for X-ray analysis of the product layers. The ESEM was equipped with EDAX detector. In addition to general EDAX measurements, $\mathrm{X}$-ray point analysis (using local area of $5 \times 5 \mu \mathrm{m}$ at magnification $2000 \times$ or spot analysis at magnification $500 \times$ ) were performed in radial direction of the steel bar, starting at $0 \mu \mathrm{m}$ (the steel surface) up to $5000 \mu \mathrm{m}$ into the bulk material (direction the edge of the specimen). For EDAX
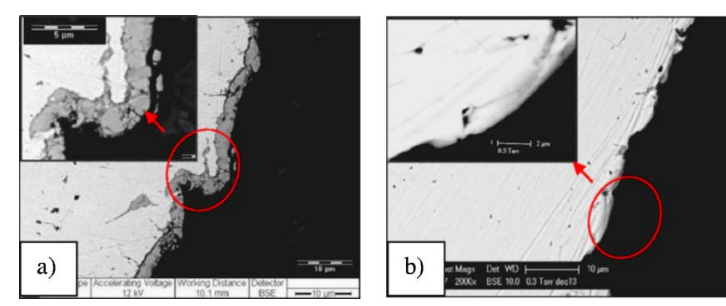

Figure 3. (Color online) Cross-sectional images of the steel/cement paste interface in (a) a protected specimen and (b) as-received specimen, revealing the product layer formed on the steel surface after conditioning for (a) 270 days and (b) the lack of product layer in the as-received specimen. analysis in the bulk material, accelerating voltage of $20 \mathrm{kV}$ was used, for composition analysis directly on the steel surface, 7 to $15 \mathrm{kV}$ was used.

\section{Results and Discussion}

$X R D$ analysis.- The study focused on the difference in chemical composition and morphological aspects of corrosion products between corroding and protected specimens. In addition the comparison among the protected specimens (under pulse $\mathrm{CP}$ and conventional $\mathrm{CP}$ ) aimed at revealing the beneficial effects of the pulse technique in terms of favorable transformations of product layers on the steel surface.

The peak intensity in the XRD diffractograms generally corresponds to the amount of specific crystalline corrosion products, thus rendering possible a qualitative comparison between different specimens. The common products on the steel surface, in the conditions under study, include iron oxides, iron (oxy)hydroxides and oxy(hydroxyl)chlorides in the presence of chlorides. Wustite $(\mathrm{FeO})$, hematite $\left(\mathrm{Fe}_{2} \mathrm{O}_{3}\right)$, magnetite/maghemite $\left(\mathrm{Fe}_{3} \mathrm{O}_{4}\right)$ are categorized in the group of oxides, while the iron oxyhydroxides vary in crystal structure $(\alpha-, \beta-, \gamma-, \delta-\mathrm{FeOOH})$ or in composition in the case of akaganeite $\left(\left[\mathrm{Fe}^{3+} \mathrm{OOHCl}\right]\right)$. Goethite $(\alpha-\mathrm{FeOOH})$ and lepidocrocite $(\gamma-\mathrm{FeOOH})$ are prominent corrosion products in rust layers, akaganeite has been identified only in layers formed through corrosion of steel in chloride environment (as in the present study). These products are present in both corroding and protected specimens; however, $\mathrm{CP}$ is expected to induce changes in proportions and morphology of the product layers.

Figure 4 shows the XRD patterns (using $\mathrm{Cu} \mathrm{K} \alpha$ radiation) for corroding (IIIN, Fig. 4a) and protected specimens [pulse CP (pDCVII middle) and conventional CP (DCVI-bottom)]. In general, the XRD pattern for the corroding specimen (IIIN, Fig. 4a) reveals sharper peaks for low valent oxides (e.g., wustite-W) and shallower peaks for magnetite (MG). In addition, akaganeite (A) is identified mainly in the corroding specimens (characteristic peak at $2 \theta 56^{\circ}$ ). Contributions of quartz-q $\left(\mathrm{SiO}_{2}\right)$, portlandite $-\mathrm{P}\left(\mathrm{CaOH}_{2}\right)$, and calcite/aragonite-C/Ar $\left(\mathrm{CaCO}_{3}\right)$ were detected along with the iron oxides and hydroxides. Quartz (Q) corresponds to sand grains; portlandite $(\mathrm{P})$ is both derived from relicts from the cement paste or from the Ca-rich layer adhered to the steel surface. The former case is valid mostly for the corroding specimen as the $\mathrm{P}$ peaks are relatively shallow. The latter case of a Ca-rich layer more adhered to the steel surface is valid for the protected specimens, particularly for pulse $\mathrm{CP}$ (middle pattern) as the portlandite peaks are much sharper (e.g., the peaks at $2 \theta 34.2^{\circ}$ and $46.5^{\circ}$ ). $\mathrm{CO}_{2}$ is obviously contributing to the products formation as the peaks at $2 \theta 29.17^{\circ}$ (and $2 \theta 43^{\circ}$ partly overlapping with the magnetite peak) are present in all specimens. The $\mathrm{CO}_{2}$ penetration seems however to have been more pronounced in the corroding specimen (IIIN) as supported by the addi- 

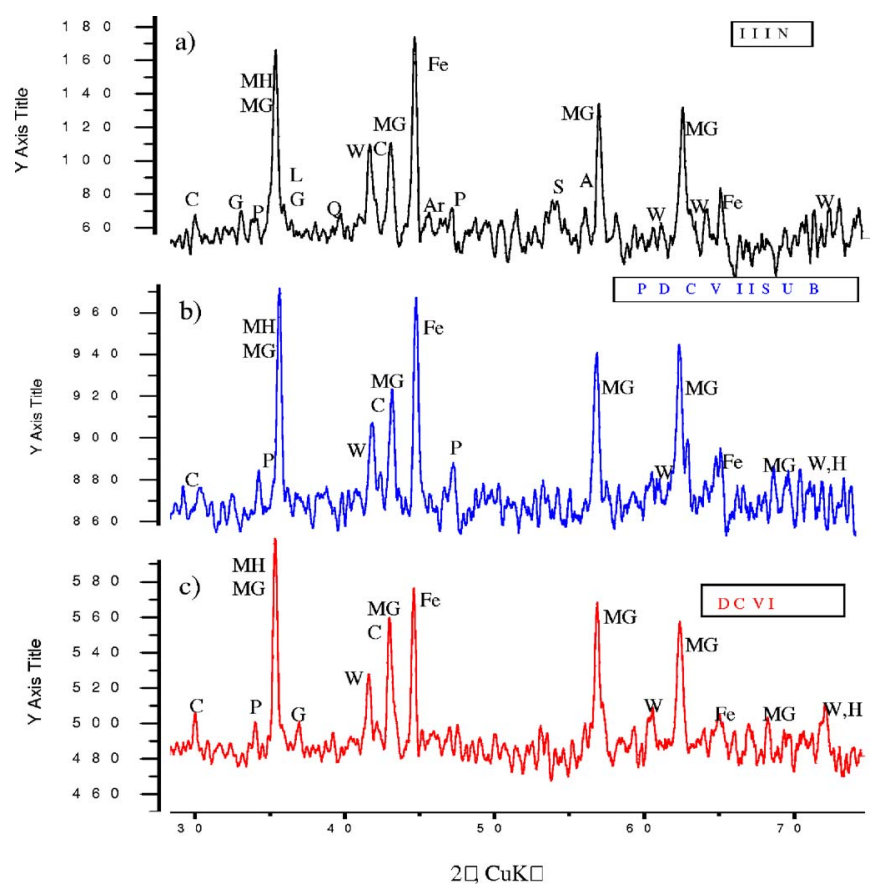

Figure 4. (Color online) XRD patterns for (a) corroding specimen, (b) protected specimen under pulse $\mathrm{CP}$, and (c) protected specimen under conventional $\mathrm{CP}$, using $\mathrm{Cu} \mathrm{K} \alpha$ radiation: $\mathrm{C}$ calcite, $\mathrm{G}$ goethite, $\mathrm{MG}$ magnetite, $\mathrm{MH}$ maghemite, $\mathrm{L}$ lepidocrocite, $\mathrm{Q}$ quartz, $\mathrm{W}$ wustite, Ar aragonite, $\mathrm{P}$ portlandite, $\mathrm{A}$ akaganeite, $\mathrm{H}$ hematite, and $\mathrm{S}$ siderite.

tional peaks at $2 \theta 45.6^{\circ}$ for aragonite and $2 \theta 54^{\circ}$ for siderite. The siderite peak is overlapping with a shallow peak for akaganeite, leading to a multipeak pattern in the range of $2 \theta 54^{\circ}$ to $54.6^{\circ}$ for the corroding specimen.
The main characteristic differences in the XRD patterns for the three specimens are:

1. The patterns for the protected specimens (Fig. 4b and c) present more magnetite (MG, $\mathrm{MH})$, corresponding to peaks $2 \theta$ $35.5^{\circ}, 43^{\circ}, 57^{\circ}, 62.5^{\circ}$, and $67^{\circ}$, respectively.

2. Compared to the protected specimens, the corroding specimen (Fig. 4a) shows relatively high amount of wustite (W) at $2 \theta 42^{\circ}$, presence of lepidocrocite (L) and goethite $(\mathrm{G})$ at $2 \theta 36.5^{\circ}$ (overlapping partly with magnetite) and a characteristic peak for akaganeite $\left(2 \theta 56^{\circ}\right)$. Siderite and aragonite $(\mathrm{S}, \mathrm{Ar})$ are present in the corroding specimen, which along with $\mathrm{L}, \mathrm{G}$, and A are barely detected in the protected specimens.

3. The proportions of high valent oxides, particularly magnetite for the protected specimens are higher. Compared to conventional $\mathrm{CP}$, the specimens under pulse $\mathrm{CP}$ show favorable composition of the product layers, evidenced by the relatively sharper peaks for magnetite, in addition to the absence of a distinguished peak for goethite at $2 \theta 37^{\circ}$ and sharper peaks for portlandite at $2 \theta 34.2^{\circ}$ and $2 \theta 46.5^{\circ}$.

Hence, the pulse $\mathrm{CP}$ brings about favorable modifications of the corrosion products in terms of higher amounts of protective $\mathrm{Fe}_{3} \mathrm{O}_{4}$, adhering to the steel surface, which along with the $\mathrm{Ca}$-rich layer (evidenced by adhered portlandite) and oxy(hydroxy) chlorides, nondetectable by XRD, denotes for better efficiency, compared to the conventional $\mathrm{CP}$.

$X$-ray photoelectron spectroscopy.- The XPS analysis supports the findings from XRD in terms of amounts and composition of corrosion products. The XPS spectra are presented in Fig. 5, the identified compounds are summarized in Table. II. The fitting of $\mathrm{O}$ $1 \mathrm{~s}, \mathrm{Ca} 2 \mathrm{p}$, and $\mathrm{C} 1 \mathrm{~s}$ spectra revealed the presence of $\mathrm{CaCO}_{3}$ in all specimens. Iron oxyhydroxides and iron oxides are present in different amounts as well, the former enriching the product layers in corroding specimens and conventionally protected specimens (IIIN and VIDC), the latter (the iron oxides) more pronounced in specimens under pulse $\mathrm{CP}$ (VIIpDC). The most intensive peak for $\mathrm{Fe}$ is the one for the corroding specimen, shifted toward lower binding energy, corresponding to $\mathrm{Fe}^{2+}$ in $\mathrm{FeO}$ at $709.6 \mathrm{eV}$, while for the


Figure 5. XPS spectrums (a) $\mathrm{O} 1 \mathrm{~s}$, (b) $\mathrm{Ca}$ 2p, (c) C 1s, (d) Si 2p, and (e) Fe 2p, and for corroding (IIIN), pulse CP (VIIpDC) and conventional CP (VIDC) specimens, using Al K $\alpha$ X-ray source (excitation energy $h v=1486.6 \mathrm{eV})$. 
Table II. Compounds according Fe 2p, O 1s, Ca 2p, and C 1s spectra and relevant binding energy.

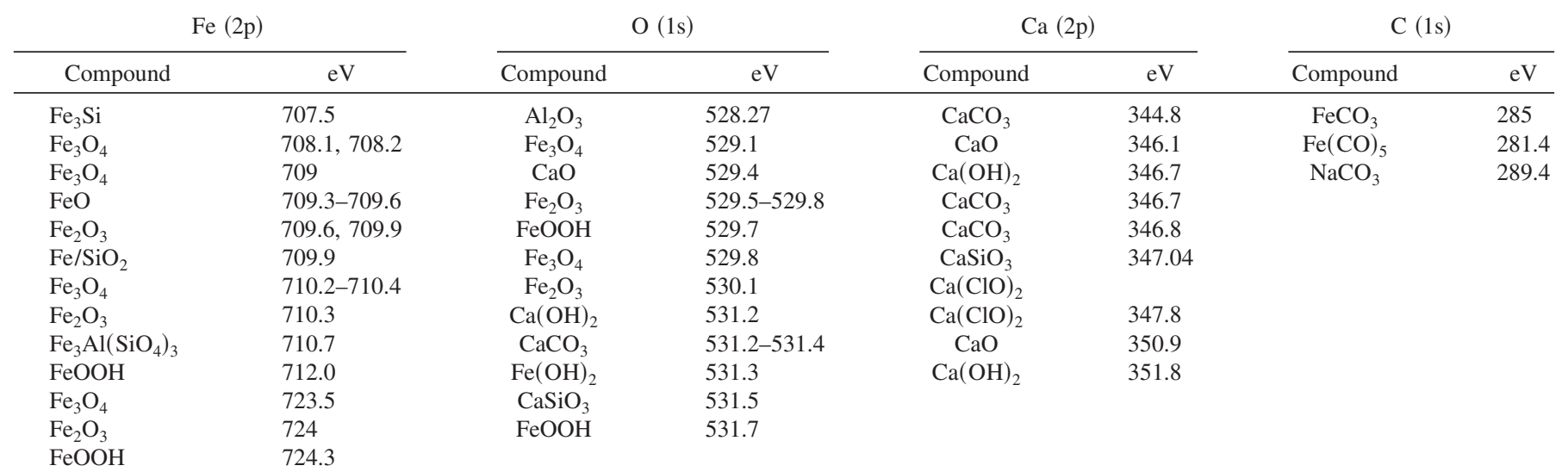

protected specimens, the corresponding peaks are at $710.2 \mathrm{eV}$ for $\mathrm{Fe}_{3} \mathrm{O}_{4}$ or $\alpha-\mathrm{Fe}_{2} \mathrm{O}_{3}$, which is consistent with the observations according the $\mathrm{O} 1 \mathrm{~s}$ spectrum.

There is a high energy broadening of the O1s spectrum for the corroding specimen (IIIN), which can be attributed to higher chloride concentration and denoted to bound water on the surface layer. Consequently, the formation of more hydrated iron compounds is more likely for the corroding specimen, hence the amount of iron oxyhydroxides $(\mathrm{FeOOH})$ is higher, as identified by XRD.

Such distribution is also reported in Ref. 25 for similar systems, where the presence of chlorides results in thicker films in which the contents of $\mathrm{FeOOH}$ and water tend to increase. The binding energy of $531.87 \mathrm{eV}$ for the corroding specimen (Fig. 5a) is attributed to $\mathrm{OH}-\mathrm{M}$ bonds, while binding energies 530.26 and $530.46 \mathrm{eV}$ for the protected specimens (pulse $\mathrm{CP}$ and $\mathrm{CP}$, respectively) are attributed to $\mathrm{O}-\mathrm{M}$ bonds. Hence the presence of $\mathrm{Fe}_{2} \mathrm{O}_{3}$ and $\mathrm{Fe}_{3} \mathrm{O}_{4}$ in protected specimens is more pronounced.

The Fe 2p spectra (Fig. 5e) reveals the following: for corroding specimen (IIIN), binding energy 709.3 and $709.6 \mathrm{eV}$ correspond to $\mathrm{FeO}$ and $\mathrm{Fe}_{2} \mathrm{O}_{3}$, respectively; for the protected specimens, binding energy 710.2 and $710.4 \mathrm{eV}$ correspond to $\mathrm{Fe}_{3} \mathrm{O}_{4}$ and $712 \mathrm{eV}$ to $\mathrm{FeOOH} . \mathrm{Fe}_{3} \mathrm{O}_{4}$ is most likely more pronounced in specimens under pulse $\mathrm{CP}$ (higher intensity of the peak at the relative binding energy-VIIpDC), while $\mathrm{FeOOH}$ is most likely in higher amounts in the corroding specimen and the protected specimen VIDC as they depict wider peaks, with larger surface area at this relevant binding energy $(712 \mathrm{eV})$. The oxidation states of iron could correspond to a $\mathrm{Fe}_{3} \mathrm{O}_{4}$ or to a mixture of $\mathrm{FeO}$ and $\gamma-\mathrm{Fe}_{2} \mathrm{O}_{3}$. As $\mathrm{Fe}_{3} \mathrm{O}_{4}$ (an inverse spinel) is structurally similar to the mixture of $\mathrm{FeO}$ and $\gamma-\mathrm{Fe}_{2} \mathrm{O}_{3}$, ${ }^{26}$ no difference between the two oxides can be measured with XPS. ${ }^{15}$ However, the broadening of the $\mathrm{Fe} 2 \mathrm{p}$ peaks for both protected specimens towards binding energy of $715 \mathrm{eV}$ can be interpreted as an indication of the change in relative concentration of the $\mathrm{Fe}^{2+}$ and $\mathrm{Fe}^{3+}$ ions in the $\mathrm{Fe}_{3} \mathrm{O}_{4}$ structure.
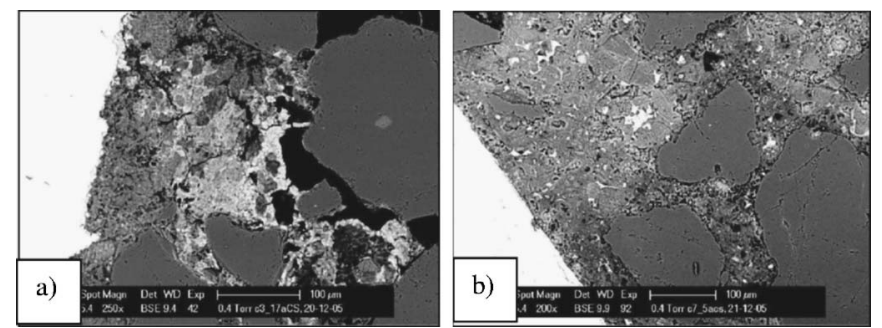

Figure 6. Cross-sectional images of the steel/cement paste interface in (a) corroding specimen, at $250 \times$ and (b) protected specimen at $200 \times$ in BSE mode. The white bright regions represent the steel surface.
Morphological and microstructural observations.- SEM imaging was employed for evaluating the morphology of product layers and their distribution in the vicinity of the steel/cement paste interface. The investigations were performed on cross sections of the specimens, which visualize the characteristic changes relevant to bond strength and mechanical properties respectively. Longitudinal sections of the steel surface and the corresponding "steel prints" on the cement paste were investigated as well. The analysis was coupled with EDAX for evaluation of the chemical composition of corrosion and cement hydration products.

Figure 6 presents the cross section of the steel/cement paste interface of the corroding and protected specimens. The significant corrosion attack on the steel surface in the corroding specimen (Fig. 6a) is clearly visible along with shrinkage cracking of the cement paste.

The microcracking is a result from the volume expansion of the corrosion products which at first occupy the restricted space around the steel bar, fill in cracks and voids and penetrate further into the bulk material. In contrast, the protected specimen presents a compact steel/paste interface (Fig. 6b), with no visible significant damage, although $\mathrm{CP}$ was applied at 120 days of age, i.e., after corrosion was certainly initiated on the steel surface taking into consideration the extreme environmental conditions.

The corrosion process on the steel surface of the protected specimens was obviously arrested and no further growth of corrosion products occurred, resulting in a dense layer, enriched in calcium (Fig. 7b), in contrast to the cracks and voids as consequence from corrosion products growth and further penetration into the bulk material, as observed in the corroding specimens at the same age (Fig. 7a).
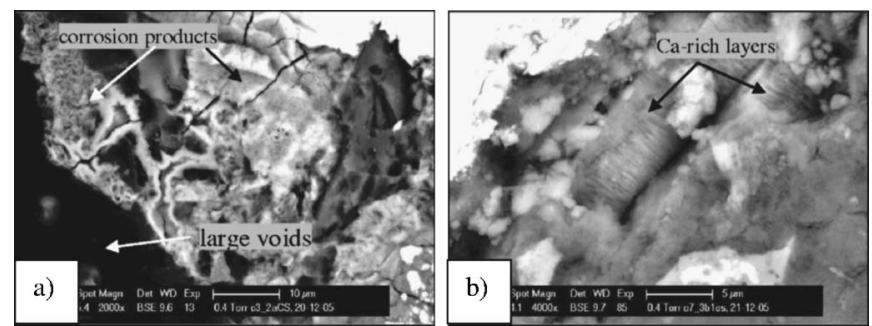

Figure 7. Higher magnification $(2000 \times)$ of the steel/cement paste interface in (a) corroding and (b) protected specimens, revealing the significant bond strength degradation due to corrosion products penetration into the bulk paste (a) and calcium-rich layer, adhered to the steel surface in the protected specimen (b). 




Figure 8. Longitudinal sections of the steel surface in (a) corroding, (b) pulse $\mathrm{CP}$ protected, and (c) conventional $\mathrm{CP}$ protected specimens.

Longitudinal sections of corroding and protected specimens (steel surface) are presented in Fig. 8. The severe corrosion damages on the steel surface of the corroding specimen are evident (Fig. 8a), whereas the steel surface of the protected specimens (Fig. 8b and c) is comparatively uniform.

Comparing specimens under pulse CP (Fig. 8b) and specimens under conventional CP (Fig. 8c) it is seen that for the specimen under pulse $\mathrm{CP}$ a more adherent layer of cement paste (enriched in calcium) covers the steel surface. The observation is consistent with the higher amounts of portlandite, detected by XRD analysis. Of course the distribution of calcium-rich layers (e.g., $\mathrm{CaO}$ and $\left.\mathrm{Ca}(\mathrm{OH})_{2}\right)$ is not uniform; however, cement paste layers more adhered to the steel surface mean lower amount of corrosion products which normally increase the bond degradation process.

As mentioned, the $\mathrm{CP}$ was expected to bring about changes in crystallinity and morphology of product layers on the steel surface. The findings from the XRD and XPS analysis were confirmed with microscopical observations of these layers, revealing higher amounts and crystalinity of the corrosion products in corroding specimens, compared to protected specimens, both at same age of 270 days. The observations are supported by energy dispersive $\mathrm{X}$-ray analysis, results of the latter for the most relevant compounds are summarized in Table III.

Figure 9 presents layers of lepidocrocite $(\gamma-\mathrm{FeOOH})$ in the corroding specimen (a) and the protected specimen (pulse CP) (b). Figure 10a presents the needlelike morphology of akaganeite, identified in the corroding specimen only. The presence of akaganeite supports the hypothesis for high salinity in the corroding specimens as it is found only in chloride containing environments. ${ }^{21-23}$

Akaganeite is mainly responsible for microcracking in reinforced concrete as it is less adherent and not accommodating in rust layers, ${ }^{21}$ thus impeding the formation of a film with good protective properties. It tends to grow in the weak zones of the paste/gravel or the steel/paste interfaces (Fig. 10b), which along with its typical needlelike structure additionally promotes microcracking. The microstrutural observations are supported by the XRD analysis with the characteristic pick for akaganeite at $2 \theta 56^{\circ}$, corresponding to planer distance $d=1.64 \AA$.
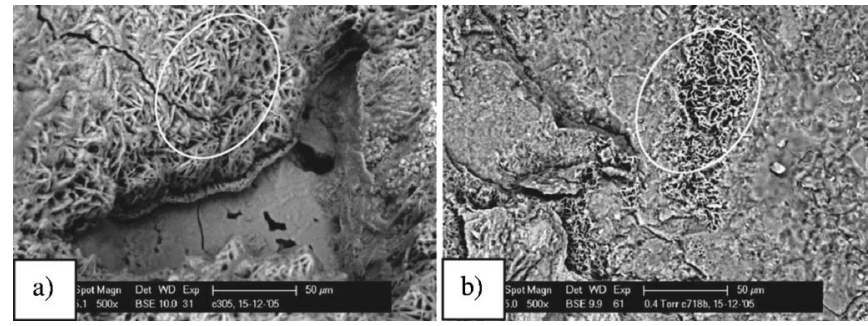

Figure 9. Different dimensions of $\gamma-\mathrm{FeOOH}$ in the (a) corroding specimen grown on a flat layer of magnetite, showing significantly higher cristallinity (crystal length about $17.5 \mu \mathrm{m}$ ) compared to the small residue of $\gamma$-FeOOH (crystal length about $8 \mu \mathrm{m}$ ), nested in the magnetite layer of a (b) protected specimen.

Along with the formation of certain corrosion products as consequence of the presence of chlorides, the carbonate compounds contribute to the overall process of product layers formation, especially in the corroding specimens. The findings from XRD and XPS analysis were supported by morphological observations. Figure 11 presents carbonate containing compounds on the steel surface of a corroding specimen Fig. 11a and on a "print" in the cement paste adjacent to the rebar Fig. 11b. Figure 11a presents a variety of corrosion products on the steel surface, depicting a large formation of siderite (left side of the image, zoomed region incorporated in the micrograph), along with colonies of lepidocrocite and goethite (Fig. 11a-middle zone). The different morphology, presented on Fig. $11 \mathrm{~b}$ is attributed to the higher chloride concentration in the adjacent paste and the formation of complex compounds with the calcium containing cement.

Geothite was expected to be present in both corroding and protected specimens with more significant formations in the corroding specimens. A formation of goethite (most probably mixed with lepidocrocite) is presented in Fig. 12b (the right side of the image), depicting needles growing in globular ("flowery") forms. The layer of mixed oxyhydroxides is adjacent to a large local damage on the steel surface, filled in with amorphous layer of most likely intermediate compounds. Figure 12a presents the formation of low crystalline geothite in the protected specimen, showing the typical globular, but whiskery and finer structure, compared to the corroding specimen.

The formation of the product layer, adherent to the steel surface, comprises at least 2 layers (as already introduced above). In the protected specimens, the inner layer contains $\mathrm{Fe}^{2+}$ and $\mathrm{Fe}^{3+}$, forming magnetite (as evidence by XRD and XPS). The outer layer will contain mainly $\mathrm{Fe}^{3+}$ and will have a more porous structure and poor conductivity. This hypothesis is evidenced by the poorly crystalline

Table III. Summarized data from EDAX analysis of the corrosion products, depicted on the micrographs (the wt $\%$ do not equal $100 \%$ as the table contains only compounds, relevant to the discussion).

Composition (most relevant compounds) (wt \%)

\begin{tabular}{|c|c|c|c|c|}
\hline Figure & Products & $\mathrm{Cl}_{2} \mathrm{O}$ & $\begin{array}{c}\mathrm{Fe}_{2} \mathrm{O}_{3} \\
\text { (iron oxides and hydroxides) }\end{array}$ & $\mathrm{CaO}$ \\
\hline Fig. 9 & Lepidocrocite $(\gamma-\mathrm{FeOOH})$ & 0.67 & 77.46 & 12.29 \\
\hline Fig. 10a & Akaganeite $\left[\mathrm{Fe}^{3+}(\mathrm{O}, \mathrm{OH}, \mathrm{Cl})\right]$ & 3.56 & 75.18 & 0.10 \\
\hline Fig. $12 \mathrm{~b}$ & Geothite $(\alpha-\mathrm{FeOOH})$ & 0.60 & 75.09 & 4.21 \\
\hline Fig. 13 (flat regions) & Magnetite $\left(\mathrm{Fe}_{3} \mathrm{O}_{4}\right)$ & 0.21 & 83.11 & 2.57 \\
\hline Fig. 14a ("pit") & Inner product & 1.02 & 66.29 & 0.18 \\
\hline \multirow[t]{2}{*}{ corroding sample } & Outer layer (pit wall) & 1.15 & 62.89 & 0.23 \\
\hline & Adjacent flat (carbonated laver) & 0.86 & 70.46 & $0.18\left(32.4 \% \mathrm{CO}_{2}\right)$ \\
\hline Fig. 14b ("pit") & Inner product & 0.11 & 41.67 & 6.41 \\
\hline protected sample & Outer adjacent layer (magnetite) & 0.20 & 77.97 & 2.63 \\
\hline
\end{tabular}



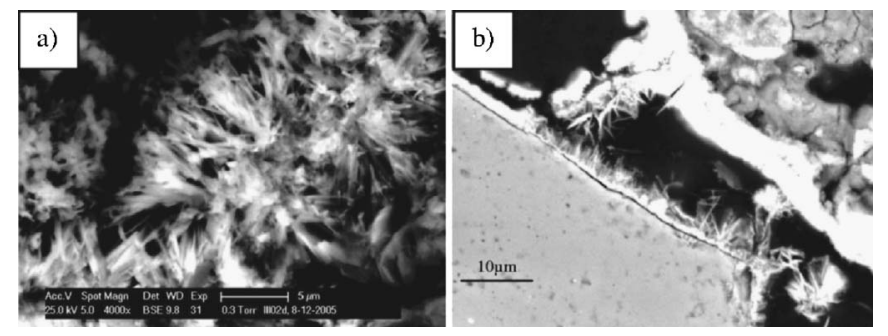

Figure 10. Needlelike morphology of (a) akaganeite in the corroding specimen, growing preferentially in voids or weak zones, as cement paste/ aggregate, thus causing significant de-bonding and microcracking (b).

goethite in the protected specimen (Fig. 12a). For the corroding specimens, the crystallinity of lepidocrocite (Fig. 9a) and goethite (Fig. 12b) is higher.

Another significant difference in the morphology of product layers in protected and corroding specimens is the appearance of the so called "inner" layer, composed from $\mathrm{Fe}_{3} \mathrm{O}_{4}$. Figure 13 presents magnetite deposits in protected and corroding specimens. The images were taken on longitudinal sections of the adherent to the steel bar concrete layer, on a "print" from the steel surface in the cement paste, i.e., the top layer is the one adhering to the steel (marked area).

The magnetite layer in the protected specimen is far more compact (Fig. 13a), while the product layer in the corroding specimens is rough from the steel-side and spongy in the direction of the paste. The former feature would denote for lower protective properties, the latter will favor restructuring and conversion of these layers in case of changed environment.

Certain product morphology is observed on the surface of the corroding specimens in the regions of localized corrosion. Figure 14a shows local corrosion damage, grown on a layer enriched in carbonates (plate morphology on the right side of the image). The
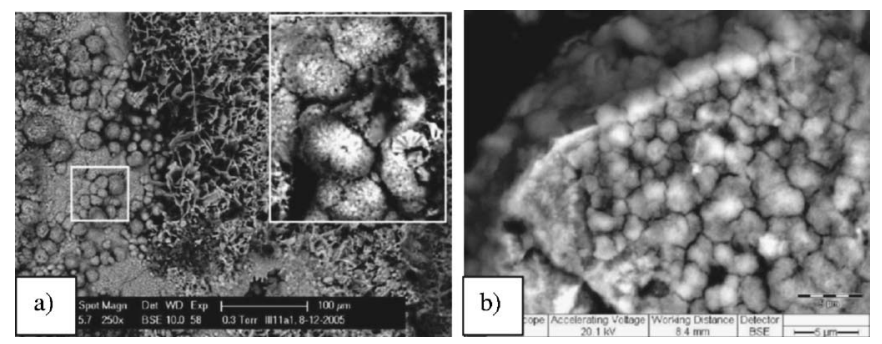

Figure 11. Steel surface morphology of (a) corroding specimen, revealing globular shape of siderite (zoomed area) and intermediate, carbonate containing compounds, deposited on the cement paste in the vicinity of the steel surface in the corroding specimen (b).

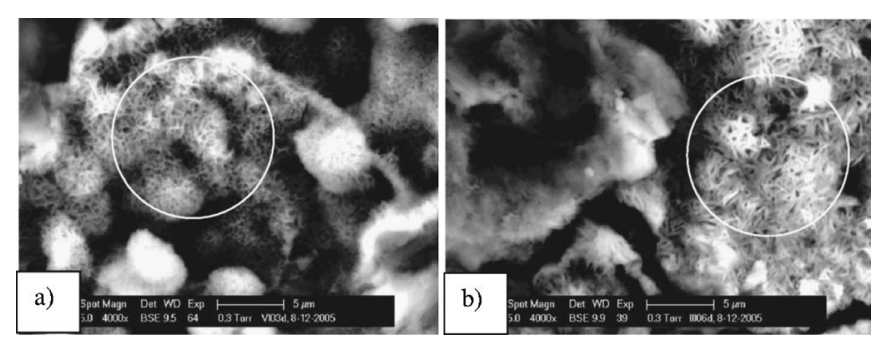

Figure 12. Formations of goethite in (a) protected specimen and (b) corroding specimen.
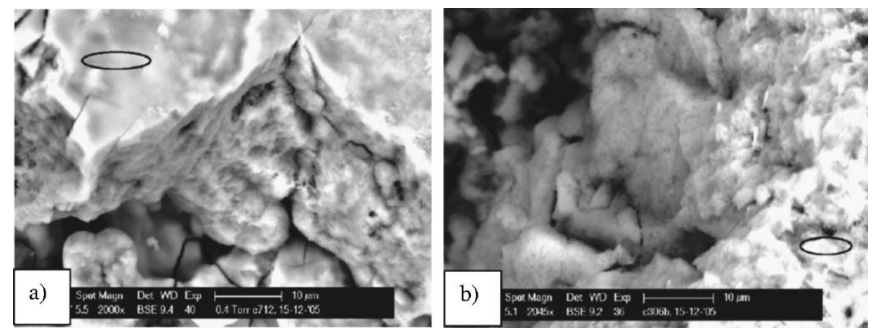

Figure 13. Magnetite deposits on the cement paste in (a) protected specimen and (b) corroding specimen.

center of the figure depicts the growth of corrosion products (most likely akaganeite and lepidocrocite) outwards of the formation, surrounded by a perpendicularly grown amorphous layer of oxy(hydroxyl)chlorides, initially formed on the steel surface.

In contrast, such local damages in the protected specimens reveal completely different morphology and composition of the products, filling in the "pits" (Fig. 14b). Local disruptions of the product layers in the protected specimens were expected as cathodic protection
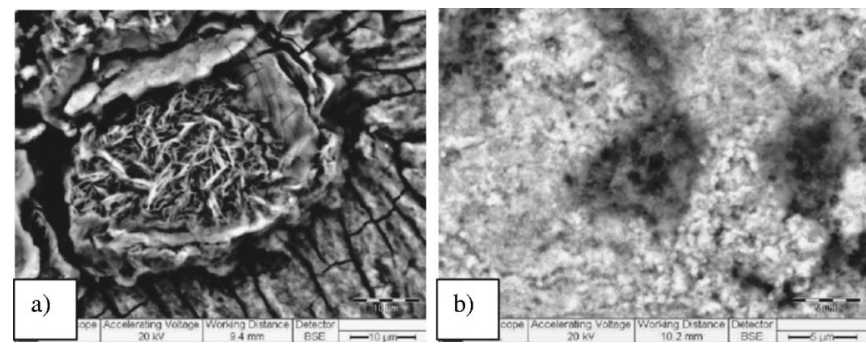

Figure 14. Localized corrosion on the steel surface in the (a) corroding specimen products locally grow in the form of a pit, surrounded by a carbonate-enriched layer; healed local damage on the surface layer (magnetite) of (b) protected specimen.

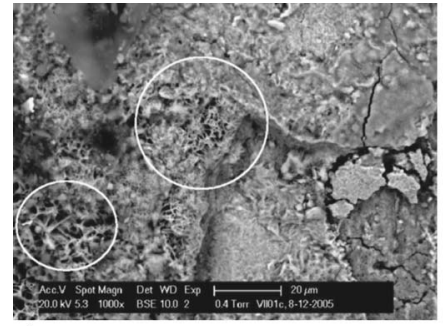

a)

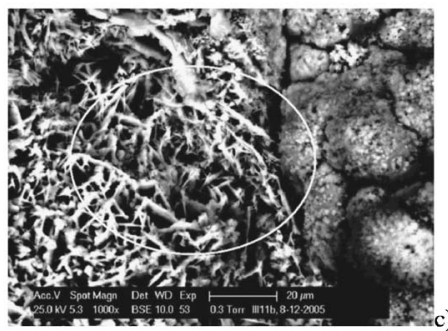

Figure 15. Product layer formation in the specimens under (a) pulse $\mathrm{CP}$, (b) conventional $\mathrm{CP}$, and (c) corroding specimen revealing the different crystallinity and morphology of the observed layers. 


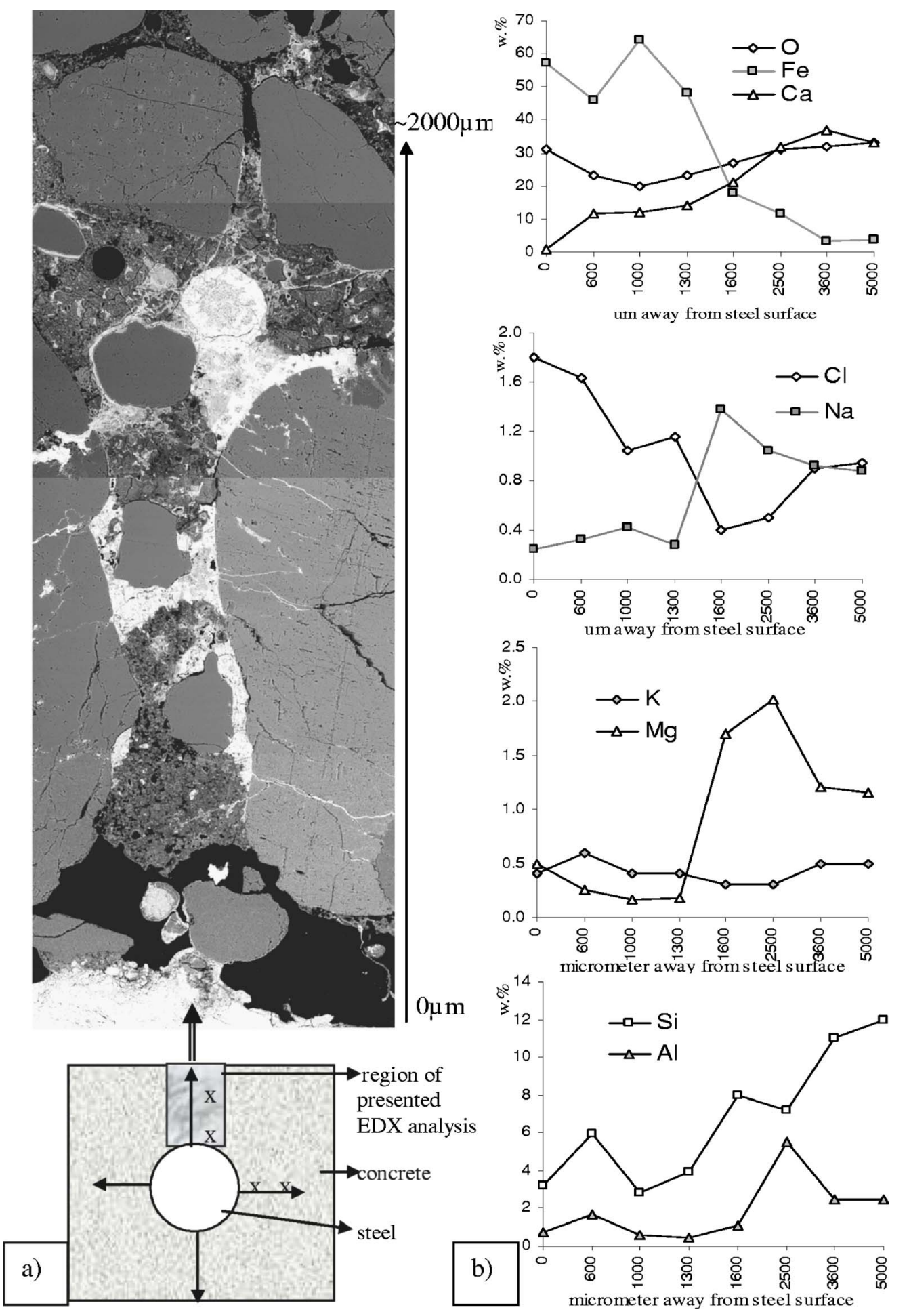

Figure 16. (a) Mounted ESEM images (cross-sectional) of corroding specimen, depicting the penetration of corrosion products into the bulk concrete matrix up to $\sim 2000 \mu \mathrm{m}$ from the steel surface (b); scheme [bottom of (a)] for the spot analysis and summarized data for ion concentrations (up to $5000 \mu \mathrm{m}$ from the steel surface into the bulk material).

was applied at 120 days of age, however as seen form Fig. 14b, these local areas are significantly smaller, are filled in with iron (oxy)hydroxides with $\mathrm{CaO}$ contributions (Table III), there is no crystalline product growth as in the corroding specimen, hence due to the changed cement chemistry as consequence from the cathodic current, these local areas in the protected specimens are "healed."
Finally, a comparison of crystallinity of corrosion products in corroding, protected (pulse $\mathrm{CP}$ ) and protected (conventional $\mathrm{CP}$ ) is presented in Fig. 15.

It is obvious that the crystallinity of corrosion products (namely nested lepidocrocite and goethite in the relatively flat layers of magnetite) for the protected specimens is much lower in the specimen 

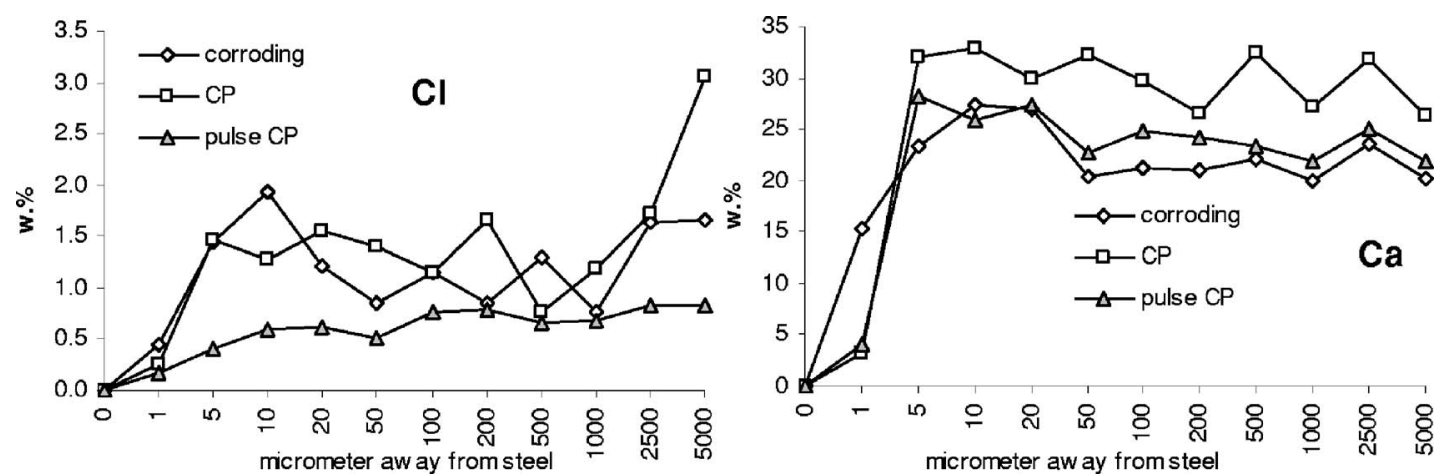

Figure 17. Chloride and calcium concentrations around the steel bars of corroding and protected specimens in wt \%, derived by EDAX spot analysis, performed from 0 to $5000 \mu \mathrm{m}$ away from the steel surface.

under pulse $\mathrm{CP}$ (Fig. 15a), compared to the conventionally protected specimen (Fig. 15b). Of course, the crystallinity of the same products in the corroding specimen is much higher (crystal length of at least $12 \mu \mathrm{m}$, Fig. 15c).

As supported by the XRD and XPS analysis, the specimen under pulse CP presents higher amounts of relatively flat magnetite. Small residues (circled regions Fig. 15a) of iron-(oxy)hydroxides (crystal length about $2-5 \mu \mathrm{m}$ ) are detected nested in the adhered magnetite layers, while the specimens under conventional CP are characterized by higher amounts of (oxy)hydroxides with higher crystallinity (crystal length about $10 \mu \mathrm{m}$ Fig. 15b). The different crystallinity, morphology, and distribution is denoted to the more favorable cement chemistry under pulse CP conditions, as supported by EDAX analysis as well, which is presented in what follows.

$X$-ray local area (spot) analysis.- As introduced in the experimental part, EDAX analysis was performed locally for the different corrosion products on the steel surface, as well as those deposited in the cement paste for all specimens. The EDAX analysis was performed as spot analysis on cross sections, using accelerated voltage of $20 \mathrm{eV}$ at $500 \times$ magnification, in radial direction from the steel bar (starting at the edge of the steel surface as distance $0 \mu \mathrm{m}$ in direction the edge of the specimen up to distance $5000 \mu \mathrm{m}$ away from the steel surface). The aim was to investigate the change in composition of the products, penetrating the bulk matrix (in case of corroding specimens) and the change in ion concentrations (of main interest chlorides and alkali) for the protected specimens. In the former case, information for how far from the steel surface corrosion products are spreading into the bulk and consequently the extent of volume expansion and microcracking can be obtained. In the latter case, the efficiency of $\mathrm{CP}$ in terms of chloride withdrawal and alkali ion accumulation in the vicinity of the steel surface can be estimated.

Figure 16a presents a schematic image of the spot-analysis around the steel bar, along with mounted micrographs (up to $2000 \mu \mathrm{m}$ only are presented, starting from the steel surface in direction of the bulk material) for the corroding specimen. Figure 16b presents the derived information for ion concentrations in wt \% (summarized trends, up to $5000 \mu \mathrm{m}$ from the steel surface into the bulk matrix).

As seen in Fig. 16a, the corrosion products have penetrated into the bulk matrix, occupying at first empty space (like pores or voids), preferentially depositing around the weakest zones (the paste/ aggregates interfaces) and causing significant bond degradation as well (the black area around the steel surface). The plots (Fig. 16b), reveal higher amounts of iron and chloride ions close to the steel surface and up to about $1600 \mu \mathrm{m}$. From this point further into the bulk the iron concentration is decreasing and alkali ions concentration increasing, i.e., accumulation of corrosion products is reduced. Oxygen distribution is more or less uniform along the whole tested area and calcium is increasing in direction of the bulk.
The same analysis (as presented above for the corroding specimen) was performed for the protected specimens, with the main interest being the distribution of chloride and alkali concentrations around the steel bars.

As seen from the plots on Fig. 17 (representing summarized trends), the chloride concentration in the immediate vicinity of the steel surface is lowest in the case of pulse CP and remains lower up to the end point of the analysis. Calcium concentration in the same areas for the pulse $\mathrm{CP}$ is lower than the conventional protection, but higher than the corroding specimen. Hence, the pulse CP promotes chloride transport away from the steel surface and thus renders favorable changes of the cement chemistry in the vicinity of the reinforcement.

\section{Conclusions}

The present study reveals the close dependence of cement chemistry and the formation, conversion, amounts, morphology, and crystallinity of the product layers on the steel surface in reinforced concrete systems. With regard to the investigated conditions of corrosion and two types of cathodic protection, the research is in terms of evaluating the changed properties of the steel surface of steel bars initially equal in appearance and surface composition. The product layer in corroding specimens is a combination of mainly low valent oxides and iron-oxy (hydroxy)chlorides, and exhibits rough morphology and higher crystallinity. Cathodic protection reduces salinity around the previously corroded steel bars, hence the product layers are more uniform and compact, exhibit lower crystallinity, and are composed predominantly of high valent iron oxides. Consequently, a more adherent and protective layer is formed. The transformation phenomena were found to be more apparent under pulse $\mathrm{CP}$ conditions, hence the pulse regime is able to arrest corrosion as efficient as the conventional CP technique on one hand, and is more favorable for the steel surface and cement chemistry in terms of morphology and microstructure on the other.

Delft University of Technology assisted in meeting the publication costs of this article.

\section{References}

1. P. Pedeferi, Constr. Build. Mater, 10, 391 (1996).

2. D. A. Koleva, J. H. W. de Wit, K. van Breugel, Z. F. Lodhi, and E. van Westing, $J$. Electrochem. Soc., 154, P52 (2007).

3. O. A. Albani, J. O. Zerbino, J. R. Vilche, and A. J. Arvia, Electrochim. Acta, 31, 1403 (1986).

4. D. S. Leek and A. B. Poole, in Proceedings of the Third International Symposium on Corrosion of Reinforcement in Concrete, Elsevier Applied Science, p. 67 (1990). 5. H. Oranowska and Z. Szklarska-Smialowska, Corros. Sci., 21, 735 (1981).

6. I. Diéz-Perez, C. Vericat, P. Gorostiza, and F. Sanz, Electrochem. Commun., 8, 627 (2006).

7. N. Sato, Corros. Sci., 31, 1 (1990).

8. Z. Szklarska-Smialovska, Corros. Sci., 44, 1143 (2002).

9. B. MacDougall and M. J. Graham, in Corrosion Mechanisms in Theory and Practice, 2nd ed., P. Marcus and J. Oudar, Editors, Marcel Dekker Inc., New York, p. 143 (2002). 
10. Y. Roh, S. Y. Lee, and M. P. Elless, Environ. Geol., 40, 184 (2000).

11. T. Misawa, Corros. Sci., 13, 659 (1973).

12. C. Sudakar, G. N. Subbanna, and T. R. N. Kutty, J. Phys. Chem. Solids, 64, 2337 (2003).

13. A. Bentur, S. Diamond, and N. S. Berke, Steel Corrosion in Concrete, p. 27, E\&FN, London (1997).

14. C. Andrade, M. Keddam, X. R. Nóvoa, M. C. Pérez, C. M. Range, and H. Takenouti, Electrochim. Acta, 46, 3905 (2001)

15. C. M. Abreu, M. J. Cristóbal, R. Losada, X. R. Nóvoa, G. Pena, and M. C. Pérez, Electrochim. Acta, 51, 1881 (2006).

16. Corrosion of Steel in Concrete, K. Tuutti, Editor, Swedish Cement and Concrete Research Institute, Stockholm, Sweden (1982).

17. T. Misawa, K. Hashimoto, and S. Shimodaira, Corros. Sci., 14, 131 (1974)

18. C. T. Lee, Z. Qin, M. Odziemhowski, and D. W. Shoesmith, Electrochim. Acta, 51,
1558 (2006).

19. A. M. van der Kraan, J. Medema, and J. Inorg, J. Inorg. Nucl. Chem., 31, 2039 (1969).

20. S. Okamoto, H. Sekizawa, and S. I. Okamoto, Reactivity of Solids, p. 341, Chapman \& Hall, New York (1972).

21. K. E. Garcia, A. L. Morlas, C. E. Arroyave, C. A. Barrero, and D. C. Cook, Hyperf Interact., 148/149, 177 (2003).

22. J. D. Bernal, D. A. Dasgupta, and A. L. Mackay, Clay Miner. Bull., 4, 15 (1959).

23. T. Misawa, T. Kyuno, W. Suetaka, and S. Shimodaira, Corros. Sci., 11, 35 (1971).

24. L. Li and A. A. Saguiés, Corrosion (Houston), 57, 19 (2001).

25. M. F. Montemor, A. M. P. Simoes, and M. G. S. Ferreira, Cem. Concr. Compos. 25, 491 (2003)

26. C. Giacovazzo, Fundamentals of Crystallography, 3rd ed., p. 442, Oxford University Press, New York (1995). 